\title{
The demand for school meal services by Swiss households
}

\author{
M. Filippini ${ }^{*} \quad$ G. Masiero ${ }^{\dagger} \quad$ D. Medici ${ }^{\ddagger}$ \\ Published in Annals of Public and Cooperative Economics (2014), 85(3): 475-495 \\ http://onlinelibrary.wiley.com/journal/10.1111/(ISSN)1467-8292
}

\begin{abstract}
In this paper we investigate the household demand for childcare during lunchtime at school using a stated preferences approach. Data are collected through phone-structured interviews to 905 residents with children in the German-speaking region of Switzerland during 2007. Poisson models with random and fixed effects are used to explore factors affecting the demand. Ordinal probit models are also considered as an alternative to count data models. The results show that price, household income, satisfaction with the current childcare service, family composition, and the area of residence significantly affect the number of weekly services demanded. We estimate that the willingness to pay for childcare during lunchtime is between 7.90 and 11.70 Swiss francs per day and does not depend on household income.

Keywords: Childcare service, school meal service, panel count data, Poisson regression, willingness to pay, ordinal probit model.
\end{abstract}

JEL classification: D12, H31, H42, J13

${ }^{*}$ Department of Economics, University of Lugano and ETH Zurich, Switzerland.

${ }^{\dagger}$ Department of Engineering, University of Bergamo, Italy and Department of Economics, University of Lugano, Switzerland. Corresponding author. E-mail: giuliano.masiero@unibg.it. The empirical analysis reported in this paper exploits a dataset built for a project commissioned to the Institute of Economics at the University of Lugano and financed by four Swiss cantons (Aargau, Basel-City, Basel-Land and Solothurn).

${ }^{\ddagger}$ Department of Economics, University of Lugano, Switzerland. 


\section{Introduction}

In most OECD countries, parents face considerable challenges when trying to reconcile their family and work commitments, since all-day childcare facilities are not always available (OECD 2007). Parents who decide to work full-time or part-time may pay a substantial amount for private childcare services. Other parents prefer to stay out of the job market and provide full-time care directly to their children. Problems with the organization of care before and after school hours and during lunchtime are substantial, particularly for families with children at primary school. Supervised school meals service and extracurricular activities may improve household choices and are probably beneficial to those parents who give value to opportunities at work.

The analysis of household preferences and willingness to pay for school meal and childcare services may represent an important step towards policies aiming at improving reconciliation between family and work life. In Switzerland, municipalities are mainly responsible for the decision to offer supervised school meal services. ${ }^{1}$ Since cantonal (state) authorities usually play a secondary role in this decision process, the supply of childcare during lunchtime and school meal services is rather heterogeneous across and within cantons. $^{2}$ In several cantons, most of the municipalities do not supply supervised school meal services but many of them have recently discussed the possibility to increase the supply. Local governments can provide a childcare and meal services during lunchtime, between morning classes and afternoon

\footnotetext{
${ }^{1}$ Usually, school time is organized in two periods: morning classes (8.30 a.m. - 11.30 a.m.) and afternoon classes (1.30 p.m. - 4 p.m.). During the lunchtime break children can have their lunch, play and rest if a school service is available, or alternatively go home.

${ }^{2}$ Switzerland is a federal State with a largely decentralized education system. Primary school education is mandatory and generally supplied by the State. The tasks of the education system are shared between three levels of government - the Confederation, the cantons and the municipalities - which work together in their respective areas of responsibility to ensure high quality in education. The organization and the regulation of the education system is not homogeneous across the territory, since each of the 26 cantons has its own subsystem of primary schools. The cantons and their municipalities are responsible for the organization and financing of primary schools. In particular, municipalities assume competences on pre-school, primary and lower secondary levels.
} 
classes. When a supervised school meal service is not available, parents look after their children between morning and afternoon classes or use some informal care mode provided by relatives, neighbours or friends. Moreover, those municipalities already providing school meal services usually set a relatively low price, which is unsatisfactory because it does not cover the average cost of the service. This pricing policy has led to financial problems. Consequently, municipalities that are interested in providing childcare and school meal services are also interested in learning more about the willingness to pay of households.

In this paper, we investigate the demand for school meals and childcare during lunchtime at primary schools in Swiss cantons characterized by a lack of supply of supervised school meal services. We consider four cantons which are representative of the northwest part of Switzerland. These cantons and their municipalities are about improving the supply of childcare services at primary school, by introducing a supervised meal service available between the end of the morning classes and the beginning of the afternoon classes. Using a stated preferences approach, we analyse the hypothetical weekly demand of school meals and childcare, conditional on household and service characteristics. First, we collect data on the weekly demand of school meals and childcare by 905 households. We then apply count data models to study factors affecting household preferences. Ordinal probit models are also considered as an alternative to count data models. Finally, we assess the willingness to pay for the new service and discuss improvements in the pricing policy for an efficient provision of school meal and childcare services.

The literature lacks empirical studies on the demand for supervised school meals. Some studies vaguely relate to our analysis, although their focus is on the demand for different types of diet rather than the demand for meals. Lee (1987) investigates the demand for varied diet in US households between 1977 and 1978. Count data approaches, such as the Poisson model and the negative binomial model, are used to examine the impact of household characteristics on the number of different food items consumed during a week. The results show that an increase in food expenditure in- 
creases the number of food items consumed at home. Moreover, the number of food items consumed at home is positively related to the number of household members. Akin et al. (1983) analyse participation in the US National School Lunch Program by 1222 children. Following the traditional utility theory, the authors write the demand for school meals as a function of the price of meals, the price of complements and substitutes, the budget constraint and several socioeconomic characteristics. A vector of nutrient taste variables is added to the demand function. The demand is estimated by means of ordered probit models where the dependent variable is the quantity of school meals. Based on the estimates, a 50 percent increase in the full price of school lunches for students is expected to reduce the participation in the National Program by 20 percent. The authors affirm that taste variables are important in assessing the demand for school meals. Park and Capps (1997) estimate the demand for prepared meals by US households using the 1987-1988 Nationwide Food Consumption Survey and applying a Heckman two-stage procedure. Prepared meals are defined as those ready to eat and to cook. Households with younger, more educated and time-constrained managers are more likely to purchase prepared meals. Income elasticities range from 0.07 to 0.13 , while own-price elasticities range from -0.23 to -0.66 . The presence of teenagers in a household is positively associated with expenditures of prepared meals. Moon et al. (2002) identify socioeconomic and demographic factors affecting the demand for varied diet as measured by the count of food items and the Entropy index. The authors use data collected in Bulgaria in 1997. Consumer preferences for food variety exhibit different patterns depending on the length of time allowed for consumption. Daily variety deviates from weekly and monthly variety and regional effects differ across periods. Finally, some studies focus on health problems related to school lunches. Schanzenbach (2009), for instance, investigates the effects of participation in the National School Lunch Program. Although initial rates of obesity are similar among participants and non-participants, the rate of obesity among participants is higher after some time.

Through this paper, we provide a first empirical analysis of the demand 
for meal and childcare services at primary school in Switzerland. Our analysis allows to disentangle factors affecting household choices and to calculate the willingness to pay for meal and childcare services at school. We believe this represents an original contribution to the modest economic literature on the demand for school meal services.

The remainder of the article is structured as follows. In Section 2, we specify a model of the demand for supervised school meals. Section 3 is devoted to the survey design and data description. In Section 4 and Section 5, we present the estimation results of our model and calculate the willingness to pay for supervised school meal services by Swiss households respectively. The use of ordinal probit models as an alternative to count data models is discussed in Section 6. Concluding remarks and policy considerations are discussed in Section 7.

\section{Model specification}

Family decisions regarding the demand for school meal and childcare services depend upon several factors, primarily job opportunities and constraints, and preferences for family life. The analysis of the relationship between household choices in the labour market and the demand for school services is beyond the scope of this paper. Instead, we focus on the demand for supervised school meals consequently to household decisions in the labour market, and try to disentangle how different family characteristics are related to this demand. Hence, we hypothesize that the household demand for school meal and childcare services is generated by the following function:

$$
Q=f(z)
$$

where $Q$ is the hypothetical number of supervised meals per week and $z$ is a vector of $k$ socioeconomic variables, including household income, and meals price.

To specify an econometric model, it is worth noticing that the dependent variable in the above equation (1) is a count variable that indicates the number of times parents buy supervised school meal services for their children 
within a week. Linear regression models are not suitable for count outcomes since the estimation results can be inefficient and biased. Models that specifically account for the generation process of the data are more suitable for count outcomes. In the literature, we find two main econometric approaches: the Poisson regression and the negative binomial regression. Some authors (Akin et al., 1983) also use ordered logit or probit models. However, the econometric literature (Greene, 2003; Cameron and Trivedi, 2005) advises count models as the most appropriate approach. ${ }^{3}$ Finally, count models offer the advantage that the calculation of consumer surplus is relatively simple. Several studies apply count models to explore, for instance, the demand for hospitalizations, the number of beverages, the number of visits to a national park, or the number of patents. Cameron and Trivedi (1986) analyse factors affecting the frequency of doctors consultations, Mullahy (1986) explores factors that influence the number of beverages, and Carpio et al. (2008) investigate the demand for agritourism in the United States.

To estimate the demand model, we first consider a Poisson regression. Unobserved heterogeneity that remains constant over time is taken into account by means of random effects $(\mathrm{RE})$ and a fixed effects (FE) versions of the Poisson panel regression. ${ }^{4}$ Our model includes several time-invariant covariates and one time-variant variable, the price. For this reason, the estimation results obtained with the fixed effects version are not very interesting. For comparison purposes with the Poisson regression, we also estimate the demand model using a negative binomial regression. The possibility of applying a two-part model and a zero-inflated count model has also been discussed. However, due to the fact that the zeros and the positive values in our sample come from the same generation process (see Section 3), these econometric approaches are not advisable (Cameron and Trivedi, 2005).

To focus on the Poisson model, we recall that the Poisson probability

\footnotetext{
${ }^{3}$ For the purpose of comparison we also estimate ordered models and report the results in Section 6.

${ }^{4}$ See Hausman et al. (1984), Cameron and Trivedi (1998), Greene (2003) and Baltagi (2008) for details on Poisson regressions for panel data.
} 
density function can be written as:

$$
P(Q=q)=\frac{e^{-\lambda} \lambda^{q}}{q !}
$$

where $q=0,1,2, \ldots$ is a random variable indicating the number of times an event occurs, and $\lambda$ is the parameter of the Poisson distribution. Precisely, $\lambda$ is the expected number of times an event occurs within a given time. This is a one-parameter distribution with both the mean and the variance of $Q$ equal to $\lambda$.

In our case, the Poisson distribution defined by (2) assumes that all families have the same expected demand in terms of the number of school meal and childcare services. Since this assumption may not be very realistic, we can allow for heterogeneity in $\lambda$ by using the following Poisson regression model:

$$
\lambda_{i}=\exp \left(z_{i} \beta\right)
$$

where $\lambda_{i}$ is a function of vector of socioeconomic characteristics of the household and price for the service $\left(z_{i k}\right)$. The subscript $i$ indicates the household and $\beta$ are parameters. Taking the exponential of $z_{i} \beta$ forces the expected count $\lambda$ to be positive, which is required by the Poisson distribution.

Socioeconomic control variables $\left(z_{k}\right)$ provide information on the price for meal service (Price), the household monthly income (Income), the structure of the family in terms of number of members and their age, the level of education, work constraints and the area of residence of the households, and satisfaction with the current care mode. More precisely, we include dummy variables to capture whether the child is cared by non-family members (Care by others $),{ }^{5}$ whether the family lives in urban or rural area (Urban), and the canton of residence $(A G, B L, B S$, or $S O)$. We also include a dummy to indicate if the respondent is the child's mother (Mother), whether or not

\footnotetext{
${ }^{5}$ Parents can ask relatives, neighbours or friends to look after their children during lunchtime. This type of childcare is usually unpaid.
} 


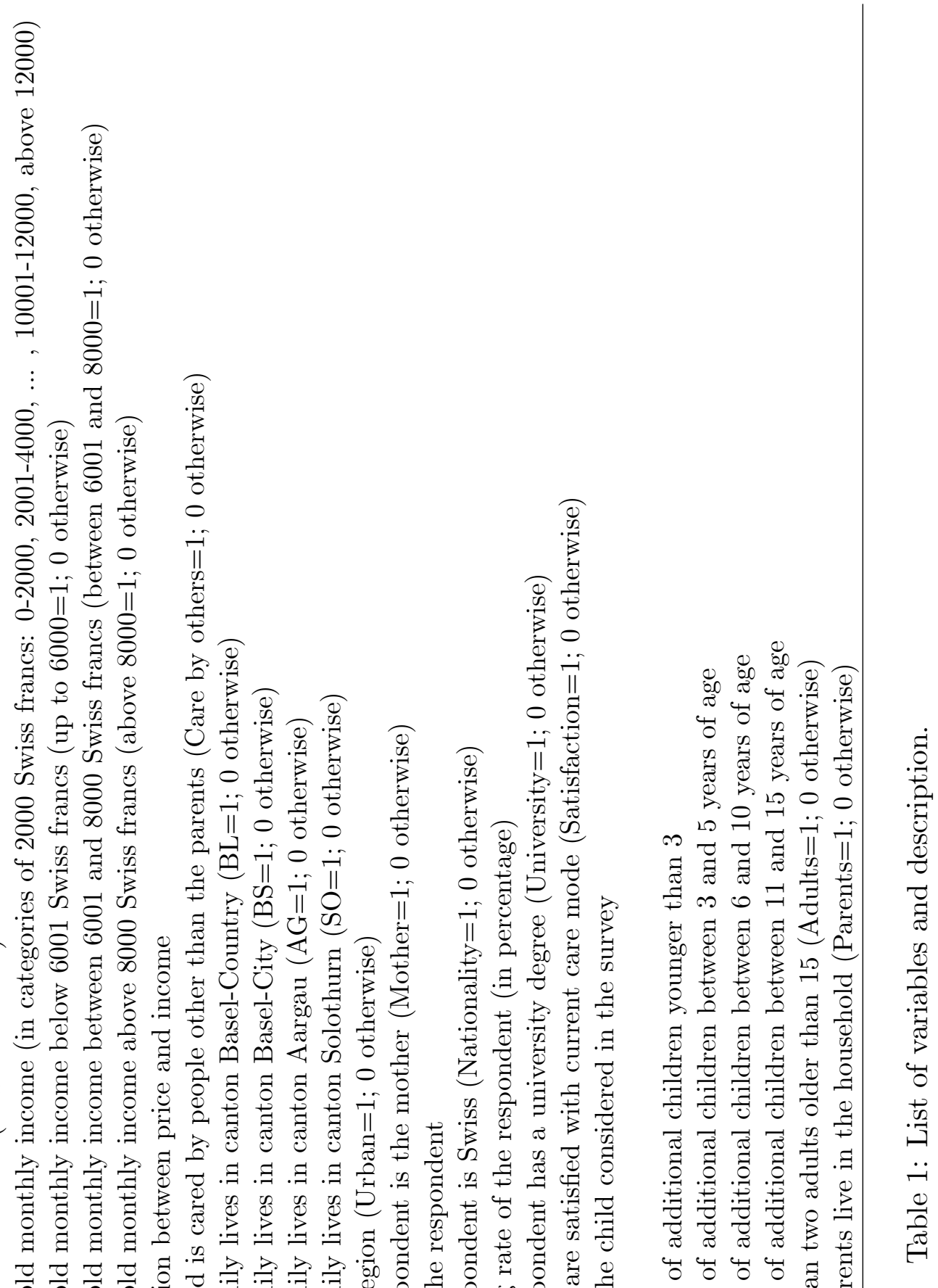

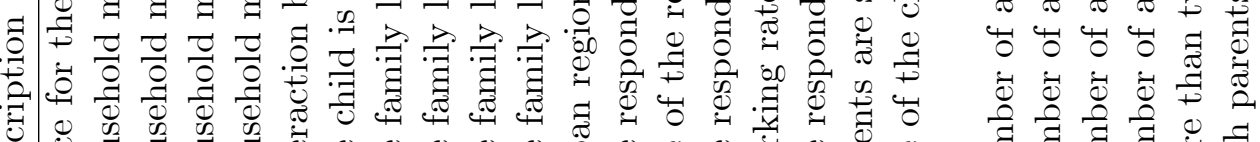

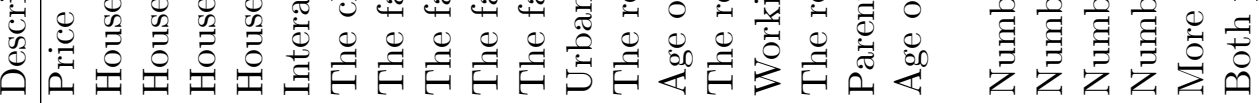

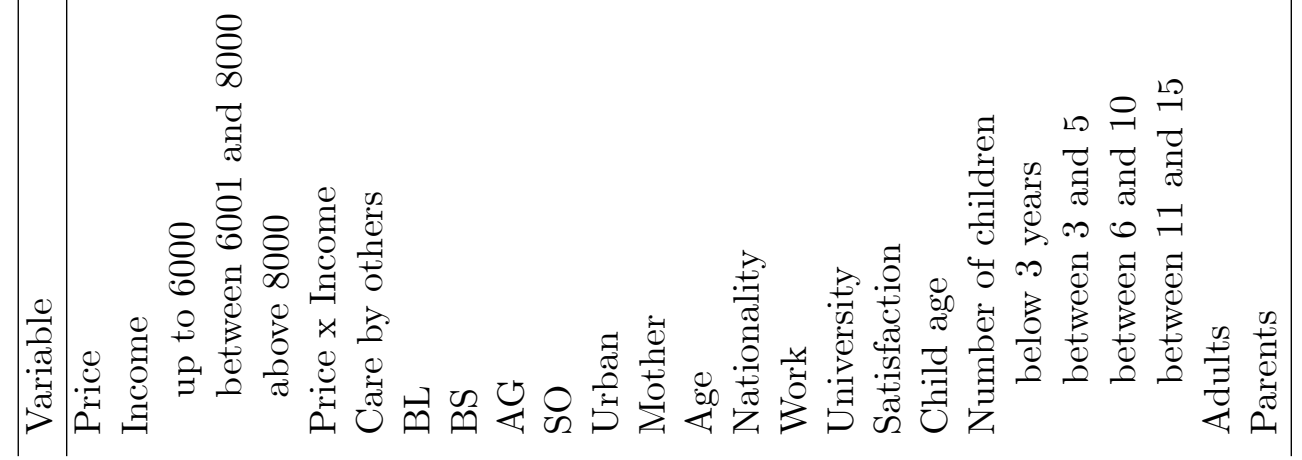


the respondent is a foreigner (Nationality), and has a university degree (University). Other covariates includes the age of the respondent (Age) and the percentage of work of the respondent (Work). In addition, we consider household satisfaction with the current care mode (Satisfaction) and the age of the child (Child age). If the family has more than one child, the number of additional children is measured by covariates for different age categories (below 3 years of age, between 3 and 5, between 6 and 10, and between 11 and 15). A dummy variable (Adults) indicates whether there are more than two adults in the household, i.e. people older than 15. Finally, we consider whether or not both parents live in the household (Parents). Socioeconomic variables are listed and described in Table 1.

Given equations (2) and (3) and the assumption that the events are independent, it is straightforward to estimate our Poisson regression parameters $(\beta)$ by means of a maximum likelihood procedure. The log-likelihood function for the Poisson regression model is given by:

$$
L(\beta)=\sum_{i=1}^{N}\left[q_{i}\left(z_{i} \beta\right)-\exp \left(z_{i} \beta\right)-\ln q_{i} !\right]
$$

where $N$ is the number of observed values $q_{i}$ in the sample.

In our model specification, the parameter estimates $(\hat{\beta})$ indicate the impacts of the $k$ th-independent variable on the number of school meal and childcare services demanded. The signs of the estimated parameters indicate the direction of the impacts. These parameter estimates can be used in several ways. $^{6}$ In this study, we mainly use the results to compute the percentage change in the expected count for a $\delta$-unit change in one of the explanatory variables, for instance a socioeconomic characteristic of the household $\left(z_{k}\right)$, holding all the other variables constant. This can be computed as:

$$
\frac{\Delta \lambda}{\lambda}=100 \times\left[\exp \left(\beta_{k} \times \delta\right)-1\right]
$$

Consequently, we will discuss the impact of changes in the socioeconomic

\footnotetext{
${ }^{6}$ See Long and Freese (2003) for a discussion on this issue.
} 
characteristics of households in terms of percentage change in the number of school meal and childcare services households are willing to purchase.

\section{Survey design and data}

To investigate the demand for supervised school meals, we adopt a stated preferences approach, i.e. we use data from hypothetical markets. This approach is driven by the limited number of municipalities currently offering supervised school meals within the country. Since families living in cantons considered in our analysis do not have the possibility to purchase supervised school meal services, their demand is not revealed.

Data were collected through phone-structured interviews administered to households with children at primary schools and living in one of the four cantons of the northwest part of Switzerland, a German-speaking region. The survey was conducted during November 2007 and a specific software helped to input the answers. The average length of an interview was about 17 minutes. The data set obtained for the analysis was part of a project commissioned to the Institute of Economics at the University of Lugano and financed by four Swiss cantons (Aargau, Basel-City, Basel-Land and Solothurn).

The interview was made of two parts. In the first part, we asked information on the demand for supervised school meal services. In the second part, we collected information on the socioeconomic characteristics of the households. Also, we collected information on the use of alternative care services when parents are unable to directly provide care to their children. At the beginning of the interview, the characteristics of a typical supervised school meal service were presented to the household. ${ }^{7}$

During 2007-2008, primary schools in our regions were attended by 63155 pupils, 32150 of which were boys (50.9\%) and 31005 girls (49.1\%). Foreign

\footnotetext{
${ }^{7}$ The school meal and childcare services start at the end of the morning classes and conclude at the beginning of the afternoon classes. During this period, children can have their lunch, play, rest or to do homework. The staff is trained to take care of children. The meal service is delivered within the school or in another building/facility nearby.
} 
pupils represented $24.7 \%$ of the children population. There were 3166 classes in total, each of them with 20 children on average. Families received a letter to explain the characteristics of the study, and a coupon to ask for participation. Around $60 \%$ of the respondent households (3645) agreed to answer the questionnaire in the form of a phone interview. However, because of budget limitation, only 905 families were randomly selected for the interview. ${ }^{8}$ The final sample was representative of the households population with children at primary school in each canton, as well as class level and children age.

Some descriptive statistics for the households sample are provided in Table 2. Households characteristics are grouped in two main categories: socioeconomic characteristics of households, and children characteristics and family composition. Note that the number of observations varies with households characteristics since not all interviewed households answered all the questions.

Concerning socioeconomic characteristics, households are initially classified according to three monthly income classes: low, medium, and high. $32 \%$ of the sample (280 families) indicate a level of income below 6001 Swiss francs per month. 36\% of families (320 households) gain between 6001 and 8000 Swiss francs per month. Finally, $32 \%$ of families (282 households) gain more than 8000 Swiss francs per month. Regarding the other socioeconomic characteristics, $83 \%$ of households live in urban areas and only $17 \%$ in rural areas. Households are equally distributed across the four cantons (25\% in each canton). Mothers are responsible for the care of children in about $91 \%$ of the cases, while fathers only in $9 \% .^{9}$ For this reason, the average level of employment of the respondent is relatively low (38\%), which corresponds roughly to two working days full-time per week. The average age of the respondent is 40 years. The respondents are Swiss in $83 \%$ of cases and have a university degree in about $13 \%$ of cases. As many as $47 \%$ of children are cared during lunchtime by people other than the parents, for instance rela-

\footnotetext{
${ }^{8}$ Given the population size, our number of respondents allows to obtain $95 \%$ confidence levels with $\pm 3 \%$ precision.

${ }^{9}$ Note also that the respondent to the questionnaire is the father in about $9 \%$ of cases.
} 


\begin{tabular}{|c|c|c|c|c|c|}
\hline Variable & Obs. & Mean/Frequency & Std. Dev. & Min & Max \\
\hline Price & 1783 & 9.92 & 5.01 & 2.5 & 22.5 \\
\hline \multicolumn{6}{|c|}{ Socioeconomic characteristics of households } \\
\hline Income & 882 & 4.13 & 1.34 & 1 & 7 \\
\hline up to 6000 & 280 & $31.75 \%$ & & & \\
\hline between 6001 and 8000 & 320 & $36.28 \%$ & & & \\
\hline above 8000 & 282 & $31.97 \%$ & & & \\
\hline Age & 905 & 40.47 & 5.50 & 21 & 88 \\
\hline Work & 902 & 37.53 & 33.37 & 0 & 100 \\
\hline Care by others & 905 & $47.18 \%$ & & & \\
\hline BL & 905 & $25.08 \%$ & & & \\
\hline $\mathrm{BS}$ & 905 & $25.08 \%$ & & & \\
\hline AG & 905 & $24.97 \%$ & & & \\
\hline $\mathrm{SO}$ & 905 & $24.86 \%$ & & & \\
\hline Urban & 905 & $83.09 \%$ & & & \\
\hline Mother & 904 & $90.93 \%$ & & & \\
\hline Nationality & 905 & $82.98 \%$ & & & \\
\hline University & 905 & $13.37 \%$ & & & \\
\hline Satisfaction & 905 & $51.27 \%$ & & & \\
\hline \multicolumn{6}{|c|}{ Children's characteristics and family composition } \\
\hline Child age & 905 & 9.25 & 2.72 & 5 & 15 \\
\hline \multicolumn{6}{|l|}{ Number children } \\
\hline below 3 & 905 & 0.10 & 0.31 & 0 & 2 \\
\hline between 3 and 5 & 905 & 0.33 & 0.51 & 0 & 5 \\
\hline between 6 and 10 & 905 & 1.04 & 0.74 & 0 & 4 \\
\hline between 11 and 15 & 905 & 0.47 & 0.69 & 0 & 3 \\
\hline Adults & 905 & $89.94 \%$ & & & \\
\hline Parents & 905 & $84.20 \%$ & & & \\
\hline
\end{tabular}

Table 2: Descriptive statistics for the household sample $(\mathrm{N}=905)$.

tives or neighbours. Only in $51 \%$ of the cases, parents are satisfied with the current childcare mode during lunchtime.

Variables related to the family composition and children's characteristics include the number of children and adults in the household as well as the age of the children. The average children age is about 9 years old. On average, households include 0.1 additional children younger than 3 , and 0.33 additional children between 3 and 5. On average, families have one additional child between 6 and 10 years old, and 0.47 additional children between 11 and 15 years old. In about $90 \%$ of households, there are more than two 
adults (older than 15), and in $84 \%$ of households both parents live together.

To collect information on the demand for supervised school meals, households were asked to consider up to five levels of price for the meal and childcare services and to state the maximum number of services they would buy at each level of price. The other characteristics of the service, for instance the number of children per staff member or the opening hours of the service, were not changed. The initial level of price was set according to household's monthly income. Respondents were asked to consider their employment status as unchanged when answering the questions. Three initial levels of price were proposed to the respondents: 2.50 Swiss francs for low-income families, 7.50 Swiss francs for medium-income families, and 12.50 Swiss francs for high-income families. To simulate the Swiss customary pricing policy, subsidized prices were proportional to household income. Thus, differences in income between rural and urban areas were indirectly considered by hypothetical prices. The initial price was then increased by 2.50 Swiss francs, repeatedly, for each income group. The experiment stopped as soon as the respondent declared he/she was unwilling to buy any unit at the proposed level of price.

Clearly, the maximum number of services a household could buy was equal to five, i.e. the number of days the supervised meal service could be available within a week. Since some of the interviewed households were not interested in the supervised school meal service, they were not asked questions regarding the willingness to purchase school meal and childcare services during lunchtime according to different levels of price. Among the 905 households 679 (75.03\%) provided information on the demand for supervised school meals (226 households were not interested in the service).

Frequencies of supervised school meals demanded at different levels of price for low-income, medium-income, and high-income households, are reported in Table 3. A total of 269 households (39.62\%) declared they were not interested or not willing to purchase supervised school meals at the proposed initial price. This implies that around $60 \%$ of households were willing to buy at least one unit of service at the lowest proposed price. Generally, 


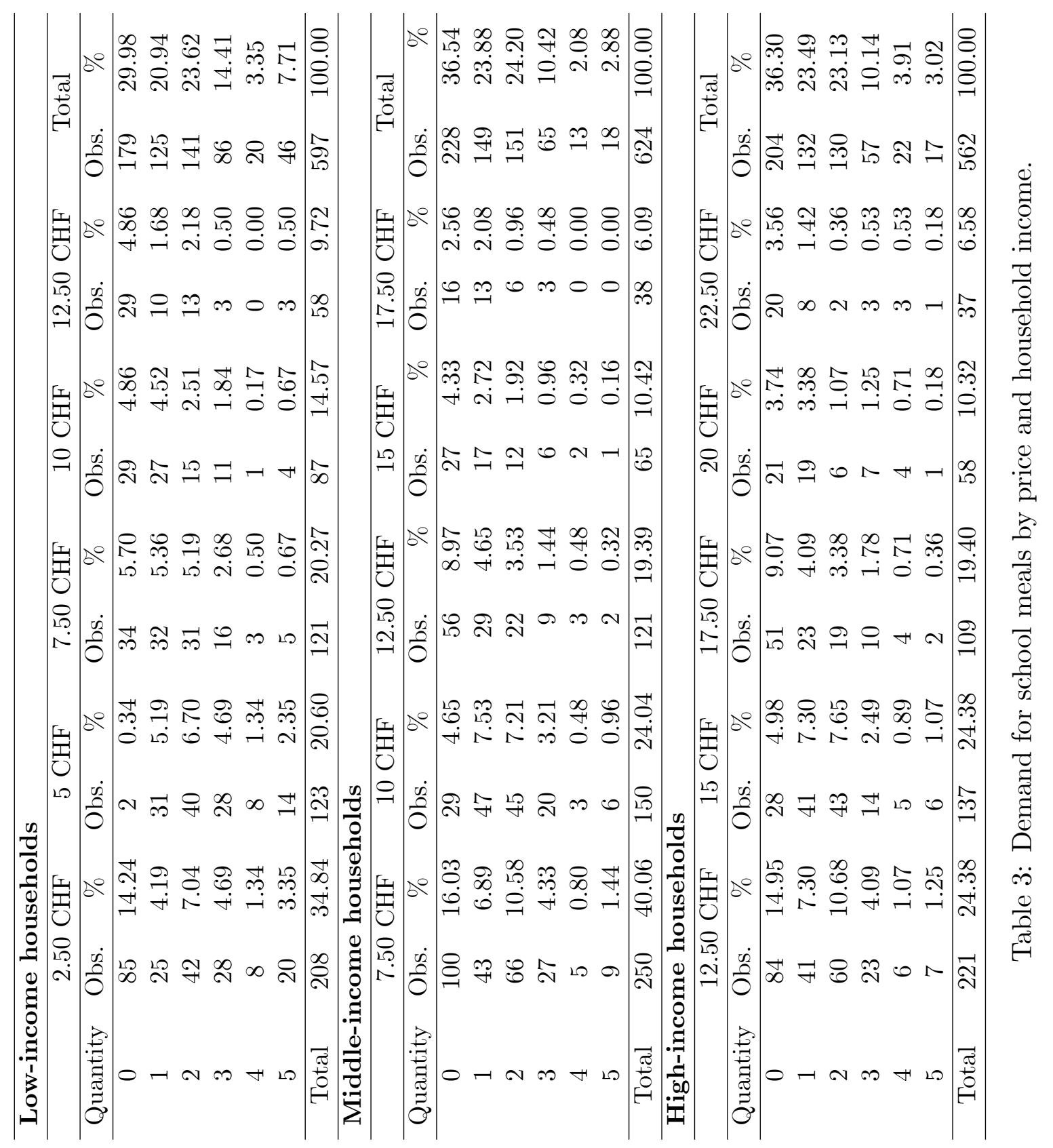


we observe that for a given level of quantity, the number of households willing to buy decreases with an increase of income, which is in accordance with the law of demand for normal goods. Moreover, the number of households demanding a certain quantity of meal and childcare services decreases when the price increases, ceteris paribus. On average, a low-income family would be willing to buy 1.56 supervised lunches during a week at the lowest proposed level of price (2.50 Swiss francs); a medium-income family would be willing to buy about 1.28 supervised lunches; and a high-income family would purchase 1.31 supervised lunches. The average price that households are willing to pay for a supervised school meal is reported in Table 2 and corresponds to 9.92 Swiss francs. ${ }^{10}$

\section{Estimation results}

Count data models help us to identify the most important factors that influence the number of school meal and childcare services demanded by households during the week. We can now present the results from the estimation of count models used to analyse the hypothetical demand for supervised school meals: a Poisson regression, a negative binomial regression, and a Poisson regression with random effects and fixed effects (see Table 4). The results of a pooled Poisson regression and a pooled negative binomial regression are reported together for the purpose of comparison. These results are similar. The use of a negative binomial regression instead of a Poisson regression is indicated in presence of significant overdispersion, i.e. when the variance exceeds the mean. We performed a simple overdispersion test statistic (a formal test on the null hypothesis of equidispersion). ${ }^{11}$ The reported $t$-statistic is asymptotically normal under the null hypothesis of no overdispersion. The coefficient of our test is 0.089 and is highly significant, which suggests that equidispersion cannot be rejected. Consequently, the

\footnotetext{
${ }^{10}$ This is obtained as the average price over families willing to purchase at least one unit of the service. Perhaps if the hypothetical prices were lower, some households would be induced to purchase services, which would affect the average.

${ }^{11}$ See Cameron and Trivedi (1990) for details.
} 


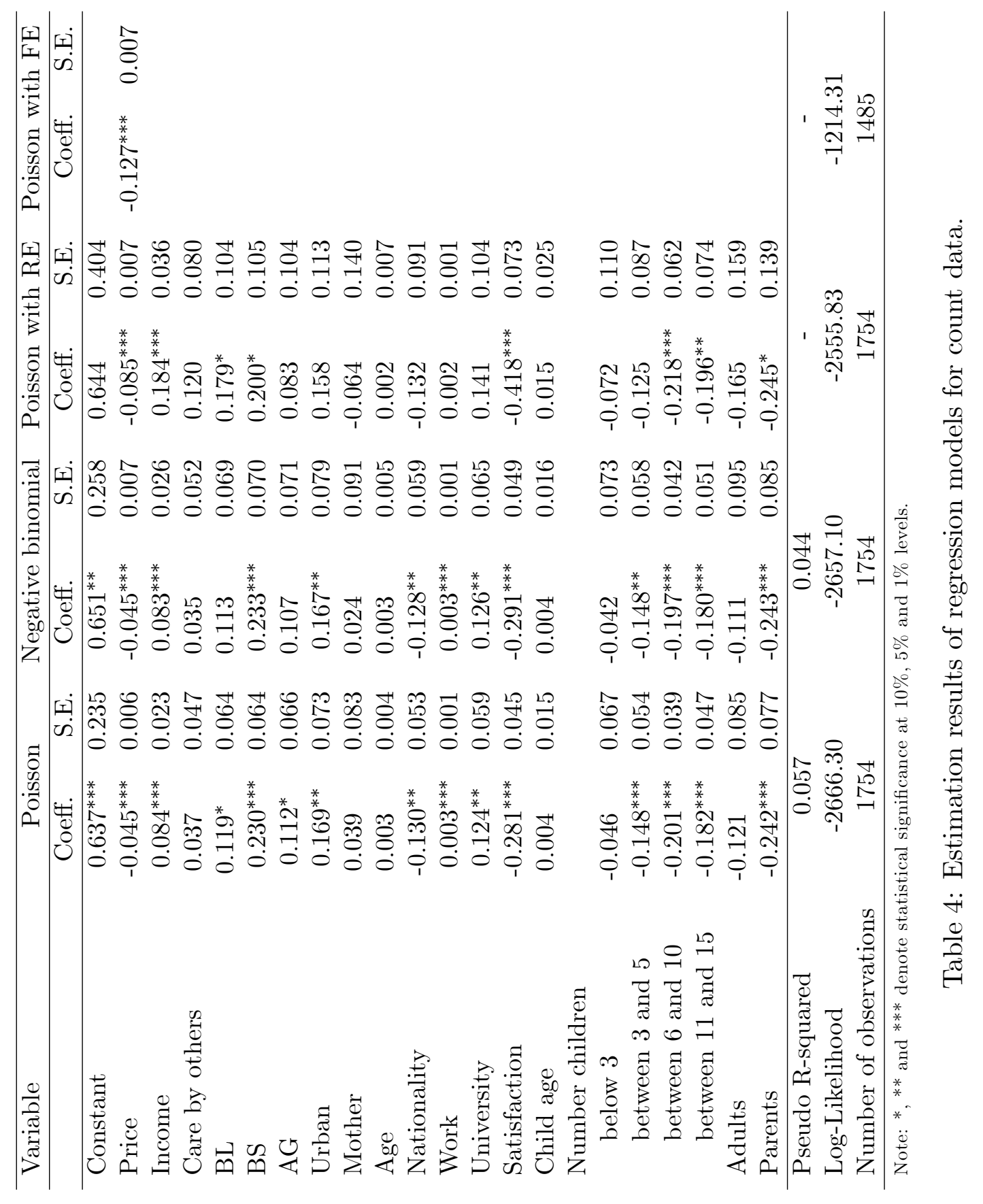


Poisson regression approach sounds appropriate. However, to take the unobserved heterogeneity that remains constant over time into account, we further estimate random effects and fixed effects versions of the Poisson panel regression and report the results in the last columns of Table $4 .^{12}$ Since we considered different initial levels of price according to household income, we also run Poisson regressions where we interact the price variable with the income variable. The goal of this model specification is to analyse whether the willingness to pay for a supervised school meal depends upon income. The estimation results will be discussed later in Section 5 to assess the willingness to pay for school meal and childcare services. We also estimate models separately for each income class. These estimations are not reported in the table since the main results are unchanged.

To briefly compare the Poisson regression and the negative binomial regressions along with the Poisson regression with random effects, note that the signs of all the coefficients are the same. Differences are observed as with respect to the level of significance. Generally, the coefficients of the Poisson with random effects are less significant than the Poisson regression and the negative binomial regression. In particular, the area of residence, the nationality, the percentage of work, the level of education, and the number of additional children between 3 and 5 years old are not significant anymore in the Poisson model with random effects.

To discuss the sign and the level of significance of the estimated parameters in more details, we can start by the price of the service. As expected, the coefficient of price is negative and highly significant. Higher levels of price would clearly decrease the number of supervised school meals demanded by households.

Focusing on children's characteristics and family composition, we observe

\footnotetext{
${ }^{12}$ The Hausman test on a reduced form of the model (only with time-invariant variables) suggests the use of fixed effects. However, as pointed out by Cameron and Trivedi (2005), an important limitation of the fixed effects approach is that the coefficients of the explanatory variables are "very imprecise" if variation over time is dominated by variation across respondents (between variation). See also Clark and Linzer (2012) for a discussion about the use of fixed effects and random effects. Moreover, as discussed before, the number of explanatory variables in the fixed effects version is limited to one.
} 
that three covariates are highly significant: the number of children between 6 and 10 years old, the number of children between 11 and 15, and the presence of both parents in the household (only in the Poisson and the negative binomial regressions). The impact of these covariates on the number of services demanded is negative. Hence, the presence of additional children and the presence of both parents decrease the number of school meal and childcare services demanded. This could be explained by the fact that parents with more children are more likely to look after their children directly and prepare meals at home. Also, the number of additional children younger than 3 and the number of additional children between 3 and 5 reduce the number of services demanded. However, the former variable is never significant, and the latter variable is highly significant in the Poisson and the negative binomial regressions. Similarly, the presence of children older than 15 is not significant. Finally, child's age has a positive impact on the number of school meal and childcare services demanded, although the effect is not significant.

Regarding socioeconomic factors, the effect of household income is positive and highly significant. As expected, a higher income is associated to an increasing number of services demanded. The level of education of the respondent and the area of residence have also a positive impact on the number of school meal and childcare services, although this impact is not highly significant in the Poisson regression with random effects. The age of the respondent is always poorly significant. Conversely, the canton of residence in the case of Basel-City and Basel-Country has a positive impact and is significant at less than $10 \%$ in the Poisson regression with random effects. This impact is measured with respect to the reference canton of Solothurn

Finally, we consider the level of satisfaction with the current care service. This indicator is related to childcare services currently used by households when children are not at school. Satisfaction with other care services has a negative and highly significant impact on the number of expected services demanded in all the regressions. This may suggest that parents who are already satisfied with the current organization of care are also likely to hold 
a satisfactory solution for lunches and, as a consequence, are not interested in the new school meal and childcare service.

Also, it is worth pointing out that possible endogeneity in employment decisions is not taken into account. The reason is that we are analyzing the hypothetical introduction of a new school meals service and, consequently, the level of employment of the household can be considered as exogenous. Unfortunately, we cannot completely rule out bias due to unobserved heterogeneity correlated with both current employment and hypothetical demand for supervised school meals.

\begin{tabular}{lcc}
\hline Variable & $\begin{array}{c}\text { Poisson with RE } \\
(\% \text { change })\end{array}$ & $\begin{array}{c}\text { Poisson with FE } \\
\text { (\% change) }\end{array}$ \\
\hline Price & -8.1 & -11.9 \\
Income & 20.2 & \\
BL & 19.6 & \\
BS & 22.1 & \\
Satisfaction & -34.2 & \\
Number children between 6 and 10 & -19.6 & \\
Number chidren between 11 and 15 & -17.8 & \\
Parents & -21.7 & \\
\hline
\end{tabular}

Table 5: Percentage change in the expected count.

Using equation (5) defined in Section 2 to compute the percentage change in the expected count for a $\delta$-unit change in one of the explanatory variables, we can interpret the impact of the coefficients of the Poisson model with random effects and fixed effects. We are interested in the percentage change in the expected count for a unit change $(\delta=1)$ in the explanatory variable, holding other variables constant. In Table 5 we report the percentage change for the significant coefficients in the Poisson regression model with random effects and fixed effects. The percentage change in the expected count for a unit change in the price of supervised school meals is $-8.1 \%$ and $-11.9 \%$, respectively. This means that an increase in the price of the service by 1 Swiss franc decreases the expected number of services demanded by households by $8.1 \%$ or by $11.9 \%$, given the other variables are held constant in the model. Since an increase in the price of the service by 1 Swiss franc roughly 
represents a $10 \%$ increase in the average level of price (9.92 Swiss francs), this implies that price elasticity of demand is between 0.8 and 1.2 , which is not far from the estimated elasticity of 0.4 found by Akin et al. (1983) for the demand for school meals in the US.

As for children's characteristics and family composition, if the number of additional children between 6 and 10 years and the number of additional children between 11 and 15 years increases by one unit, the demand of supervised school meals is expected to decrease by $19.6 \%$ and $17.8 \%$, respectively. The presence of both parents living in the household reduces the expected number of school meal and childcare services by $21.7 \%$. As for household income, an increase by one unit (that means 2000 Swiss francs) increases the expected quantity of school meal and childcare services demanded by $20.2 \%$, ceteris paribus. Families living in the canton Basel-Country and the canton Basel-City increase the expected number of supervised school meals demanded by $19.6 \%$ and $22.1 \%$, respectively, as compared to families living in canton Solothurn. Finally, parents satisfied with their current care mode are expected to reduce the expected number of school meal and childcare services by $34.2 \%$.

\section{Willingness to pay for school meal and child- care services}

The current pricing policy applied by Swiss municipalities for the provision of supervised school meals usually consists of a subsidized price which depends on household income. From the economic point of view, this policy lacks efficiency since cantons and municipalities do not match costs and benefits at the margin for the service. Since the service is highly subsidized by local governments, there may be a margin to improve efficiency by taking the willingness to pay for different categories of consumers into account.

The estimation results of the Poisson model with random and fixed effects can be used to calculate the willingness to pay for supervised school meals. The approach is discussed in details by Haab and McConnell (2002), among 
others, who use it to assess the willingness to pay for environmental and natural resources. The willingness to pay can be measured using the integral of the expected demand function estimated by the Poisson regression. The observed dependent variable $(Q)$ is assumed to be a random draw from a Poisson distribution with mean $\lambda$ and the expected demand function is:

$$
E(Q)=\lambda
$$

The value of the willingness to pay equals the area under the expected demand curve (6). Using the exponential demand function defined by equation (3) in Section 2, we can write $\lambda=\exp \left(z_{-p} \beta_{-p}\right)+\exp \left(\beta_{p} P\right)$, where $P$ is the meal price, and $z_{-p}$ is a vector of covariates other than own-price. Defining $P^{0}$ as the current meal price, consumer surplus for a meal is obtained from the integral of the expected demand function. The willingness to pay for (one unit of) the school meal service can then be calculated using the following equation:

$$
W T P(\text { meals })=\int_{P^{0}}^{\infty} e^{z_{-p} \beta_{-p}+\beta_{p} P} d P=\left[\frac{e^{z_{-p} \beta_{-p}+\beta_{p} P}}{\beta_{p}}\right]_{P=P^{0}}^{P \rightarrow \infty}=-\frac{\lambda}{\beta_{p}},
$$

when $\beta_{p}<0$. Since we want to focus on a daily meal, the willingness to pay can be derived from (7) as:

$$
W T P(\text { meal })=-\frac{1}{\beta_{p}} .
$$

Using the estimated parameter of price $\left(\hat{\beta}_{p}\right)$ from our regressions in Section 4 , we calculate that the willingness to pay for a daily meal and childcare service is between 7.90 and 11.70 Swiss francs. To our knowledge, this is the first attempt to estimate the willingness to pay for supervised school meal services. Consequently, it is not straightforward to compare our valuation with the results of other studies.

For policy discussion, we consider an average cost of approximately 20-25 Swiss francs per unit of service. This value is based on information provided by a Swiss municipality that supplies supervised school meal services. Further, the average price for a meal and child supervision for households of 
medium-income class set by the municipal authority is 12.30 Swiss francs. We observe that our estimated willingness to pay for the service is well below the full cost of the service. This implies that the provision of supervised school meal services should be highly subsidized by local governments.

Further, from the pricing strategy point of view, it would be interesting, for instance, to use information on the willingness to pay for different income categories. To calculate the effect of price for different income categories, we can slightly modify our Poisson regression with random effects using two approaches. The first approach interacts the price variable with a set of dummy variables representing different income categories, while the second approach introduces a new variable that represents the interaction between price and income.

We estimate these models in order to check whether the willingness to pay for a supervised school meal varies with income. The first model considers the interaction between price and three income categories: below 6000 Swiss francs, between 6001 and 8000 Swiss francs, and above 8000 Swiss francs. The second model includes only two income categories: below and above 8000 Swiss francs. Finally, the third model considers the interaction between price and income. Generally, the sign and the magnitude of the coefficients do not vary across the three models, except for price and income interactions. Only the significance of the workload of the respondent differs across the models. In the first two models the coefficient of Work is significant, whereas in the third model this is not significant.

The results of the three models are also similar to those of the Poisson regression with random and fixed effects reported in Table 4. The signs of the coefficients are the same. Four covariates improve their level of significance: households living in urban areas, the age of the respondent, the intensity of work (except for the third model where we interact price and income), and the level of education of the respondent. Conversely, the presence of both parents in the family is not significant anymore. Finally, the willingness to pay for school meal and childcare service does not seem to depend on household income since the interaction variables are never significant. Note, 
however, that the demand for supervised school meals is significantly and positively affected by household income, which suggests that high-income families are likely to demand more meals per week and, consequently, to spend more for weekly access to school meal services.

We are clearly aware that our estimation of the willingness to pay can be challenged, since the use of stated preferences is exposed to criticism, in particular concerning the techniques to obtain people's preferences. Stated preference survey techniques usually ask questions about the value for some non-market goods. Therefore, the methods rely on answers to questions about hypothetical situations and the results may be affected by strategic bias, yea-saying, insensitivity to scope variations and framing. ${ }^{13}$ The difference between stated and revealed values is alluded to as a hypothetical bias. We cannot exclude, for instance, that some households underestimated their willingness to pay for school meals to affect future decisions on meals price by cantonal authorities. Also, the hypothetical nature of the survey on payment and provision can result in responses that are significantly greater than actual payments. However, in our case the service is not yet available. Consequently, individuals are not aware of the actual price (revealed value) for the school meal service. Since the meal service was not implemented yet at the time of the survey, we assume that this type of strategic behaviour was negligible. Murphy et al. (2005) point out that despite the richness of studies, there is no consensus about the underlying causes of hypothetical bias or ways to calibrate survey responses for it. In other terms, it is difficult to understand why people may give a different willingness to pay on a survey than in an experiment that affects their money (Loomis, 2011). To conclude, although stated preference methods are subject to careful scrutiny, this should not be interpreted as an indication that stated preference estimates are less valid than revealed preferences estimates, as argued by Champ et al. (2003).

\footnotetext{
${ }^{13}$ See Bateman et al. (2002) and Champ et al. (2003) for more details.
} 


\section{Ordered probit estimations as an alterna- tive approach}

Following Cameron and Trivedi (1986) we consider ordered probit models as an alternative approach to count models used so far in our analysis. Even though the number of school meals appears to be a cardinal measure for school meal services, an ordinal measure approach is also possible. Hence, for instance, two school meals represent a higher level of school meal service than one, but not necessarily $100 \%$ more. Consequently, an observed variable of count form may reflect a methodological limitation in data collection. This variable is no more than a proxy measured on an ordinal scale. In our case, one could be interested in the use of school meal services rather than the total number of meals during a week. Consequently, if households maximize a utility function, a latent relationship between meals and the explanatory variables can be estimated by ordered models. This approach does not require that events arrive randomly over time according to a well defined Poisson process.

As expounded by Maddala (1983), we can treat the observed count variable $Q_{i}$ as a proxy for the variable of theoretical interest, $Q_{i}^{*}$, which by assumption is assumed to be distributed as $N\left(z_{i} \beta, \sigma^{2}\right) . Q_{i}$ is treated as a categorical variable with $J$ response categories related to the unobserved variable $Q_{i}^{*}$. The probability of choosing alternative $j$ is defined as

$$
\begin{aligned}
& \operatorname{Pr}\left(Q_{i}=j\right)=\operatorname{Pr}\left(\mu_{j-1}<Q_{i}^{*}<\mu_{j}\right) \\
& -\infty=\mu_{0}<\mu_{1}<\cdots<\mu_{J}=+\infty, j \in\{1,2, \ldots, J\}
\end{aligned}
$$

where $\mu_{j}$ s are the threshold parameters. Imposing $\sigma=1$, the ordinal probit model leads to the following probability function

$$
\operatorname{Pr}\left(Q_{i}=j\right)=\Phi\left(\mu_{j}-z_{i} \beta\right)-\Phi\left(\mu_{j-1}-z_{i} \beta\right)
$$

where $\Phi$ is the cumulative standard normal density. This equation is at the basis of the maximum likelihood estimation of parameters $\mu_{j}$ and the vector $\beta$. 
The results obtained using ordered probit regressions with and without random effects are reported in Table 6. It is worth comparing the previous estimates of count data models to those of the ordinal probit model, although the magnitude of the coefficients reported in Table 4 and Table 6 is not directly comparable. We notice that the signs of the estimated co-

\begin{tabular}{|c|c|c|c|c|}
\hline \multirow[t]{2}{*}{ Variable } & \multicolumn{2}{|c|}{ Ordered probit } & \multicolumn{2}{|c|}{ Ordered probit with RE } \\
\hline & Coeff. & S.E. & Coeff. & S.E. \\
\hline Price & $-0.051^{* * *}$ & 0.000 & $-0.224^{* * *}$ & 0.000 \\
\hline Income & $0.092^{* * *}$ & 0.002 & $0.525^{* * *}$ & 0.000 \\
\hline Care by others & 0.063 & 0.288 & $0.465^{* * *}$ & 0.005 \\
\hline $\mathrm{BL}$ & $0.138^{*}$ & 0.075 & $0.492^{* *}$ & 0.023 \\
\hline $\mathrm{BS}$ & $0.261^{* * *}$ & 0.001 & 0.208 & 0.351 \\
\hline AG & 0.116 & 0.145 & 0.150 & 0.491 \\
\hline Urban & $0.174^{* *}$ & 0.042 & 0.341 & 0.144 \\
\hline Mother & 0.079 & 0.477 & -0.027 & 0.931 \\
\hline Age & 0.002 & 0.653 & 0.004 & 0.786 \\
\hline Nationality & $-0.138^{*}$ & 0.053 & -0.281 & 0.156 \\
\hline Work & $0.004^{* * *}$ & 0.000 & 0.003 & 0.354 \\
\hline University & $0.152^{*}$ & 0.054 & 0.299 & 0.182 \\
\hline Satisfaction & $-0.340^{* * *}$ & 0.000 & $-0.920^{* * *}$ & 0.000 \\
\hline Child age & 0.010 & 0.601 & 0.056 & 0.285 \\
\hline \multicolumn{5}{|l|}{ Number children } \\
\hline below 3 & -0.060 & 0.481 & -0.217 & 0.338 \\
\hline between 3 and 5 & $-0.155^{* *}$ & 0.018 & -0.197 & 0.274 \\
\hline between 6 and 10 & $-0.230^{* * *}$ & 0.000 & $-0.469^{* * *}$ & 0.000 \\
\hline between 11 and 15 & $-0.184^{* * *}$ & 0.001 & $-0.425^{* * *}$ & 0.006 \\
\hline Adults & $-0.222^{*}$ & 0.069 & $-0.683^{*}$ & 0.057 \\
\hline Parents & $-0.219^{* *}$ & 0.042 & -0.296 & 0.337 \\
\hline Cut 1 & -0.857 & & -0.940 & 0.277 \\
\hline Cut 2 & -0.234 & & 0.025 & 0.977 \\
\hline Cut 3 & 0.520 & & 1.297 & 0.134 \\
\hline Cut 4 & 1.162 & & 2.432 & 0.005 \\
\hline Cut 5 & 1.457 & & 2.936 & 0.001 \\
\hline Log-Likelihood & \multicolumn{2}{|c|}{-2582.49} & \multicolumn{2}{|c|}{-2400.35} \\
\hline Number of observations & \multicolumn{2}{|c|}{1754} & \multicolumn{2}{|c|}{1754} \\
\hline
\end{tabular}

Note: $* * *$ and ${ }^{* * *}$ denote statistical significance at $10 \%, 5 \%$ and $1 \%$ levels.

Table 6: Estimation results of ordered probit regressions.

efficients in the Poisson model with random effects and the ordinal probit 
model with random effects are the same. Also, regarding the significance of the coefficients we see little difference. Contrary to Poisson regressions, whether the child is cared by people other than parents is highly significant in the ordinal probit model with random effects. Living in the canton Basel-Country $(B L)$ is also more significant (from $10 \%$ to $5 \%$ ) in the ordinal probit model, while living in the canton Basel-City $(B S)$ and having both parents in the same household are no longer significant. The number of additional children between 11 and 15 years old increases in significance (from $5 \%$ to $1 \%$ ) in the ordinal probit model. Finally, the dummy indicating that more than two adults older than 15 (Adults) live in the household becomes significant at $10 \%$ level. ${ }^{14}$ In conclusion, estimations with ordered probit or logit models do not lead to different considerations regarding households' choices of school meal and childcare services, as compared to the estimation approach based on count data models. Therefore, the results in terms of willingness to pay obtained in Section 5 are confirmed.

\section{Conclusions}

The provision of extra-familial care services at primary school level in Switzerland is lacking. However, a growing number of parents, especially mothers, are willing to increase their working time. As discussed in a report by the OECD (2007), an increase in the labour market participation by women is beneficial not only from the private point of view, but also for the whole economy. To improve the provision of supervised school meal services, the Swiss federal government has extended the program of financial incentives to childcare services before, during or after school. To be effective, policy makers need detailed information on the conditions under which parents are willing to use these services.

Using a stated preferences approach, we analysed households' choices concerning school meal and childcare services for children attending primary

\footnotetext{
${ }^{14}$ As a final check, we run ordinal logit regressions with and without random effects. The sign and significance of the coefficients are pretty much the same as in ordered probit models.
} 
school in four Swiss cantons. Our results attest a significant interest for the provision of supervised school meals in primary schools. The number of services demanded during a week depends mainly on the price, the household monthly income, the number of additional children between 6 and 10 years old and between 11 and 15 years old, the presence of both parents in the household, the canton of residence, and the satisfaction with the currently used care mode.

The effect of factors considered in our models may have important implications for the enactment of a school meal and childcare service in the four cantons considered. Our results may help public authorities to understand how different determinants influence households behavior, which could be taken into account to improve the supply of supervised school meal services.

Our empirical study has also two important implications for local policy makers. First, local governments could run deficits for the provision of meal and childcare services since household willingness to pay is relatively low. Second, although we observe that the number of services demanded increases with household income, we do not find evidence that high-income families are willing to pay more than low-income families for school meal and childcare provision during lunchtime. This may suggest that setting a uniform price for supervised school meals which only varies according to household income may not be effective, unless this type of price discrimination is used to redistribute income across income categories for equity reasons. 


\section{References}

AKIN J.S., GUILLKEY D.K., POPKIN B.M. and WYCKOFF J.H., 1983, 'The Demand for School Lunches: An Analysis of Individual Partecipation in the School Lunch Program', The Journal of Human Resources, 18(2), 213-30.

ALBERINI A. and LONGO A., 2006, 'Combining the Travel Cost and Contingent Behavior Methods to Value Cultural Heritage Sites: Evidence from Armenia', Journal of Cultural Economics, 30(4), 287-304.

ALBERINI A., ZANATTA V. and ROSATO P., 2007, 'Combining Actual and Contingent Behavior to Estimate the Value of Sports Fishing in the Lagoon of Venice', Ecological Economics, 61(2-3), 530-41.

BALTAGI B.H., 2008, Econometric Analysis of Panel Data, 4th Edition, West Sussex: John Wiley \& Sons Ltd.

BANFI S., FARSI M. and FILIPPINI M., 2009, 'An Empirical Analysis of Child Care Demand in Switzerland', Annals of Public and Cooperative Economics, 80(1), 37-66.

BATEMAN I.J., CARSON R.T., DAY B., HANEMANN M., HANLEY N., HETT T., JONES-LEE M., LOOMES G., MOURATO S., ÖZDEMIROGLU E., PEARCE D.W., SUGDEN R. and SWANSON J., 2002, Economic Valuation with Stated Preference Techniques: A Manual, Cheltenham: Edward Elgar.

BECKER G., 1965, 'A Theory of the Allocation of Time', The Economic Journal, 75(299), 493-517.

BEN-AKIVA M. and LERMAN S.R., 1985, Discrete Choice Analysis: Theory and Application to Travel Demand, Cambridge: The MIT Press.

CAMERON A.C. and TRIVEDI P.K., 1986, 'Econometric Models Based on Count Data: Comparison and Applications of Some Estimators and Tests', Journal of Applied Econometrics, 1(1), 29-53.

CAMERON A.C. and TRIVEDI P.K., 1990, 'Regression Based Tests for Overdispersion in the Poisson Model', Journal of Econometrics, 46(3), 34764 . 
CAMERON A.C. and TRIVEDI P.K., 1998, Regression Analysis of Count Data, New York: Cambridge University Press.

CAMERON A.C. and TRIVEDI P.K., 2005, Microeconometrics: Methods and Applications, New York: Cambridge University Press.

CAMERON A.C. and TRIVEDI P.K., 2010, Microeconometrics Using Stata, Lakeway Drive: Stata Press.

CARPIO C.E., WOHLGENANT M.K. and BOONSAENG T., 2008, 'The Demand for Agritourism in the United States', Journal of Agricultural and Resource Economics, 33(2), 254-69.

CHAMP P.A., BOYLE K.J. and BROWN T.C., 2003, A Primer on Nonmarket Valuation, Dordrecht: Bateman I.J. ed., Kluwer Academic Publishers.

CLARK T.S. and LINZER D.A., 2012, 'Should I Use Fixed or Random Effects?', Working Paper No. 1315, The Society for Political Methodology. GREENE W.H., 2003, Econometric Analysis, 5th Edition, Upper Saddle River: Prentice Hall International.

HAAB T.C. and McCONNELL K.E., 2002, Valuing Environmental and Natural Resources: the Econometrics of Non-Market Valuation, Cheltenham: Edward Elgar.

HAUSMAN J.A., HALL B.H. and GRILICHES Z., 1984, 'Econometric Models for Count Data with an Application to the Patents-R \& D Relationship', Econometrica, 52(4), 909-38.

LEE J.-Y., 1987, 'The Demand for Varied Diet with Econometric Models for Count Data', American Journal of Agricultural Economics, 69(3), 687-92. LONG J.S., 1997, 'Regression Models for Categorical and Limited Dependent Variables, Thousand Oaks: Sage.

LONG J.S. and FREESE J., 2003, Regresion Models for Categorical Dependent Variables Using Stata, Revised Edition, College Station: Stata Press. LOOMIS J., 2011, 'What's to Know About Hypothetical Bias in Stated Preference Valuation Studies?', Journal of Economic Surveys, 25(2), 363-70. LOUVIERE J.J. and HENSHER D.A., 1983, 'Using Discrete Choice Models with Experimental Design Data to Forecast Consumer Demand for a Unique Cultural Event', Journal of Consumer Research, 10(3), 348-61. 
LOUVIERE J.J., HENSHER D.A. and SWAIT J.D., 2000, Stated Choice Methods: Analysis and Application, Cambridge: Cambridge University Press. MADDALA G.S., 1983, Limited-dependent and Qualitative Variables in Econometrics, Cambridge: Cambridge University Press.

McCULLOCH C.E., SEARLE S.R. and NEUHAUS J.M., 2008, Generalized, Linear, and Mixed Models, Hoboken: Wiley.

MOON W., FLORKOWSKI W.J., BEUCHAT L.R., RESURRECCION A.V., PARASKOVA P., JORDANOV J. and CHINNAN M.S., 2002, 'Demand for Food Variety in an Emerging Market Economy', Applied Economics, 34(5), 573-81.

MULLAHY J., 1986, 'Specification and Testing of Some Modified Count Data Models', Journal of Econometrics, 33(3), 341-65.

MURPHY J.J., ALLEN P.G., STEVENS T.H. and WEATHERHEAD D., 2005, 'A Meta-Analysis of Hypothetical Bias in Stated Preference Valuation', Environmental and Resource Economics, 30(3), 313-25.

OECD, 2004, Babies and Bosses: Reconciling Word and Family Life, Vol. 3: New Zealand, Portugal and Switzerland, Paris: OECD.

OECD, 2007, Babies and Bosses: Reconciling Work and Family Life, A Synthesis of Findings for OECD Countries, Paris: OECD.

PARK J.L. and CAPPS O., 1997, 'Demand for Prepared Meals by U.S. Households', American Journal of Agricultural Economics, 79(3), 814-24.

PORTNEY P.R. and MULLAHY J., 1986, 'Urban Air Quality and Acute Respiratory Illness', Journal of Urban Economics, 20(1), 21-38.

SCHANZENBACH D.W., 2009, 'Do School Lunches Contribute to Childhood Obesity?', The Journal of Human Resources, 44(3), 684-709.

STERN S., BANFI S. and TASSINARI S., 2006, Krippen und Tagesfamilien in der Schweiz. Aktuelle und zukünftige Nachfragepotenziale, Bern: Haupt. THOMAS A., 2000, Économétrie des Variables Qualitatives, Paris: Dunod. 